\title{
FORMAÇÃO DOS GRADUANDOS DE PEDAGOGIA, EDUCAÇÃO INCLUSIVA E TECNOLOGIA ASSISTIVA: O QUE PENSAM OS FUTUROS PROFESSORES
}

TRAINING OF PEDAGOGY GRADUATES, INCLUSIVE EDUCATION AND ASSISTIVE TECHNOLOGY: WHAT FUTURE TEACHERS THINK

\section{FORMACIÓN DE GRADUADOS DE PEDAGOGÍA, EDUCACIÓN INCLUSIVA Y TECNOLOGÍA ASISTIVA: LO QUE PIENSAN LOS PROFESORES FUTUROS}

\section{RESUMO}

Educadores e pesquisadores brasileiros concordam que a perspectiva atual da inclusão dos alunos com deficiência e outras necessidades educacionais especiais exige o repensar da escola, de modo a proporcionar ensino de qualidade para todos os alunos, sem exceção. Para que isso ocorra, a formação de professores torna-se essencial. O principal objetivo desta pesquisa foi investigar a percepção dos graduandos do curso de Pedagogia de uma universidade pública do Rio de Janeiro quanto a abordagem do tema Educação Especial e Inclusiva dentro do currículo do curso e refletir sobre a TA no âmbito da formação inicial de professores. O método do estudo foi um survey envolvendo 18 alunos da graduação de Pedagogia. O estudo foi desenvolvido em salas de aula da Faculdade de Educação onde foi aplicado um questionário. Os dados foram analisados quantitativamente e qualitativamente. Os resultados sugerem que os graduandos de fato não se sentem preparados para atuar com alunos com deficiência e outras NEEs. Trazem ainda pontos importantes para a reflexão sobre o currículo oferecido. Seriam eles: a reorganização das ementas das disciplinas a fim de evitar que um mesmo conteúdo seja dado em mais de uma disciplina, oferta mais diversificada de eletivas, inserção de disciplina de práticas pedagógicas e de estágio curricular na área.

Submetido em: 18/03/2020 - Aceito em: 13/04/2020 - Publicado em: 29/04/2020

${ }^{1}$ Graduada em Pedagogia pela Universidade do Estado do Rio de Janeiro.

2 Professora Adjunta da Faculdade de Educação da Universidade do Estado do Rio de Janeiro. Pós Doutorado em Educação pela Universidade do Estado do Rio de Janeiro. Doutora em Educação pela Universidade do Estado do Rio de Janeiro, integrante do Grupo de Pesquisa Linguagem e Comunicação Alternativa e coordenadora do Laboratório de Tecnologia e Comunicação Alternativa vinculado ao Programa de Pós-Graduação em Educação (PROPEd) da UERJ. Membro da Sociedade Internacional em Comunicação Alternativa ISAAC. Membro da Associação Brasileira de Comunicação Alternativa. 


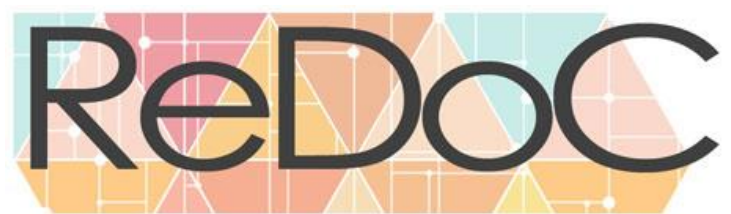

\title{
Revista Docência e Cibercultura
}

Palavras-chave: Formação Inicial de Professores. Educação Especial. Educação Inclusiva. Tecnologia Assistiva.

\begin{abstract}
Brazilian educators and researchers agree that the current perspective of including students with disabilities and other special educational needs requires rethinking the school in order to provide quality education for all students, without exception. For this to occur, teacher training is essential. The main objective of this research was to investigate the perception of undergraduate students of the Pedagogy course of a public university in Rio de Janeiro regarding the approach of the theme Special and Inclusive Education within the curriculum of the course and to reflect on TA in the scope of initial teacher education. The study method was a survey involving 18 students of the Pedagogy degree. The study was developed in classrooms at the Faculty of Education where a questionnaire was applied. The data were analyzed quantitatively and qualitatively. The results suggest that undergraduates do not really feel prepared to work with students with disabilities and other NEEs. They also bring important points for reflection on the offered curriculum. They would be: the reorganization of the subjects' menus in order to avoid that the same content is given in more than one discipline, a more diversified offer of electives, insertion of the discipline of pedagogical practices and curricular internship in the area.
\end{abstract}

Keywords: Initial Teacher Training. Special education. Inclusive education. Assistive Technology.

\section{RESUMEN}

Los educadores e investigadores brasileños coinciden en que la perspectiva actual de incluir a los estudiantes con discapacidades y otras necesidades educativas especiales requiere repensar la escuela para proporcionar una educación de calidad para todos los estudiantes, sin excepción. Para que esto ocurra, la formación del profesorado es esencial. El objetivo principal de esta investigación fue investigar la percepción de los estudiantes de pregrado del curso de Pedagogía en una universidad pública de Río de Janeiro con respecto al enfoque del tema de Educación Especial e Inclusiva dentro del plan de estudios del curso y reflexionar sobre la Tecnología Asistiva en el contexto de la formación inicial del profesorado. El método de estudio fue una encuesta que involucró a 18 estudiantes del grado de Pedagogía. El estudio se desarrolló en las aulas de la Facultad de Educación donde se aplicó un cuestionario. Los datos fueron analizados cuantitativa y cualitativamente. Los resultados sugieren que los estudiantes universitarios no se sienten realmente preparados para trabajar con estudiantes con discapacidades y otros NEE. También aportan puntos importantes para la reflexión sobre el plan de estudios ofrecido. Serían: la reorganización de los menús de las asignaturas para evitar que se dé el mismo contenido en más de una disciplina, una oferta más diversificada de asignaturas optativas, la inserción de la disciplina de prácticas pedagógicas y prácticas curriculares en el área.

Palabras clave: Formación inicial del profesorado. Educación Especial. Educación inclusiva. Tecnología Asistiva.

\section{INTRODUÇÃO}

O debate sobre a formação dos professores para atuar na Educação Inclusiva em nosso país cresce a cada a dia. As discussões incluem não só a formação continuada do professor como também a formação inicial, oferecida nas instituições de ensino superior, assim como as condições de trabalho dos docentes e o desenvolvimento profissional (PLETSCH, 2009; 
SCHIRMER, 2012; MANZINI, 2012; CORTELAZZO, 2012; CALHEIROS et al., 2018).

Compreendemos que os professores têm um papel essencial a desempenhar nessa perspectiva inclusiva e que para isso é necessário mais do que apenas incluir na grade curricular "conhecimentos relativos a educação do aluno com necessidades educacionais especiais (NEE)" como prevê o parecer do CNE/CP nº 9, de 8 de maio de 2001 (BRASIL, 2001, p.26). Este documento deu início a uma mudança nos currículos dos cursos de graduação das licenciaturas, que começaram a incluir em suas grades curriculares algumas disciplinas obrigatórias e/ou eletivas que abordassem o tema (CORTELAZZO, 2012). Mas dentro de uma sociedade tão dinâmica, onde o conhecimento cresce e as informações se transformam a cada instante, quais pontos seriam primordiais na formação do futuro educador na proposta inclusiva? Como fazer uma seleção de temas que fossem considerados "suficientes" para serem abordados durante uma graduação?

Bueno (1999) afirma que um dos pilares principais da educação inclusiva plena é a formação efetiva dos profissionais para atuaram nessas escolas:

“Todas essas considerações nos mostram que, pelo menos no que tange à uma política de formação docente, estamos longe de alcançar níveis qualitativos mínimos para a consecução de uma educação inclusiva (BUENO, 1999, p.17).

Cortelazzo (2012) crítica a ausência de discussões tanto no aspecto histórico sobre a inclusão, deficiência e NEE quanto em disciplinas como fundamentos sociológicos, filosóficos e antropológicos na graduação das licenciaturas. A autora questiona como um professor pode ter competência para tratar desse alunado, conversar com seus pares e dialogar com os profissionais de atendimento especializado se durante a sua graduação não houve essa discussão interdisciplinar.

São inúmeras as dificuldades encontradas para a implementação de uma educação que seja verdadeiramente inclusiva. Entre essas, está a falta de conhecimento e prática dos profissionais da área de educação, principalmente os relacionados a Tecnologia Assistiva (TA), para lidar com a diversidade de alunos existentes (PLETSCH, 2009; BERSCH, 2009; SCHIRMER, 2012; PEDROSO; CAMPOS; DUARTE, 2013). A organização do conceito de TA no Brasil é recente

\begin{tabular}{|l|l|} 
v. 4 & n.1
\end{tabular}
p. 83 
e foi sistematizada com a criação do Comitê de Ajudas Técnicas (CAT), em 2006, que após ampla pesquisa do referencial teórico internacional aprova, em 2007, o conceito brasileiro de Tecnologia Assistiva:

[...] uma área do conhecimento, de característica interdisciplinar, que engloba produtos, recursos, metodologias, estratégias, práticas e serviços que objetivam promover a funcionalidade, relacionada à atividade e participação, de pessoas com deficiência, incapacidades ou mobilidade reduzida, visando sua autonomia, independência, qualidade de vida e inclusão social (BRASIL, 2007, p.3).

Manzini (2012) defende que o docente deve incorporar, em sua prática, as novas tecnologias educacionais, cujo conceito subjacente é que essa tecnologia seria uma forma de auxílio para alunos com deficiência. Este fato se deve a uma base formativa que pouco aborda essa escola inclusiva, que abrange tantas especificidades. O principal objetivo deste estudo foi investigar a percepção dos graduandos do curso de Pedagogia de uma universidade pública do Rio de Janeiro quanto à abordagem do tema Educação Especial e Inclusiva dentro do currículo do curso e refletir sobre a TA no âmbito da formação inicial de professores.

\section{METODOLOGIA}

O método do estudo foi um survey envolvendo um grupo de alunos da graduação de Pedagogia.

Participantes. Participaram da pesquisa 18 alunos da graduação de Pedagogia.

Local. O estudo foi desenvolvido em salas de aula da Faculdade de Educação da universidade. Instrumentos. Nesse estudo foi utilizado um questionário. Este foi organizado com duas questões fechadas, seis questões semiabertas e duas questões abertas para caracterização dos participantes e a compreensão das concepções dos graduandos de pedagogia sobre a formação recebida na área da educação especial e inclusiva. também foram utilizadas as ementas das disciplinas da área da Educação Especial e Inclusiva do Departamento de Estudos da Educação Inclusiva e Continuada (DEIC) da universidade.

Procedimentos gerais e específicos. O projeto foi submetido à apreciação da Direção da Faculdade de Educação, que o aprovou. Para a realização do survey que caracterizou os graduandos do curso de Pedagogia e suas concepções sobre a formação inicial recebida na área 
da Educação Especial e Inclusiva primeiramente a pesquisadora conversou informalmente com alunos da Pedagogia abordando o tema da pesquisa. A partir das suas experiências como graduanda e com base nos relatos dos colegas a pesquisadora elaborou o questionário da pesquisa. Este foi avaliado pela orientadora que retornou com algumas sugestões e questionamentos. Então com base em todos os aspectos levantados a pesquisadora organizou o questionário versão final. Os critérios adotados para a escolha da amostra foram: alunos que estivessem cursando Pedagogia, entre o $6^{\circ}$ e $8^{\circ}$ períodos e que tivessem interesse em participar da pesquisa. Foram convidados alunos desses períodos pois já haveriam passado pelas disciplinas obrigatórias da área de Educação Especial e Inclusiva, que são ofertadas no $1^{\circ}, 3^{\circ} \mathrm{e}$ $5^{\circ}$ períodos.

Os graduandos dos últimos períodos do curso foram então convidados a participar da pesquisa entre os dias 28 de fevereiro a 01 de março de 2018. Após a apresentação da pesquisa, aqueles que aceitaram participar assinaram o Termo de Consentimento Livre e Esclarecido (TCLE). Após a assinatura do TCLE, os alunos responderam ao questionário.

Os alunos responderam ao questionário impresso e o entregaram para a pesquisadora no mesmo dia.

Também foram analisadas de forma qualitativa as ementas das disciplinas da área da Educação Especial e Inclusiva do DEIC.

Análise de Dados. O questionário continha perguntas fechadas, semiabertas e abertas, possibilitando uma análise quantitativa e qualitativa. No estudo foram realizadas análises quantitativas das questões fechadas e análise de conteúdo das questões descritivas. A técnica utilizada foi a de análise categorial, que funciona por operações de desmembramento do texto em categorias, segundo reagrupamentos analógicos (BARDIN, 1997). Os dados coletados nas perguntas fechadas dos estudos foram organizados em banco de dados, usando-se o software Microsoft Word e Office Excel. O primeiro, auxiliando a organização dos dados em categorias, para facilitar a análise, e o segundo, auxiliando a quantificação dos resultados e possibilitando a criação de gráficos ilustrativos. A regra de enumeração considerada nas análises quantitativas foi a frequência de aparição de cada categoria de resposta. Nas análises qualitativas a inferência 


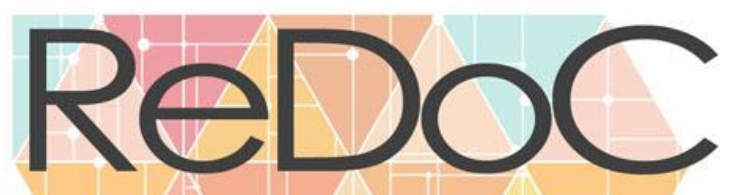

Revista Docência e Cibercultura

foi fundamentada na presença do tema ou palavra e não sobre a frequência de sua aparição. A pré-análise consistiu na leitura de todos os dados coletados através dos questionários. Para que o estudo pudesse ser compreendido e interpretado de forma correta, foi necessário vislumbrálo em sua totalidade, para que os significados pudessem surgir. Segundo Molina (1999), faz-se necessário uma análise das unidades que, articuladas, dão forma à análise. Estas unidades são chamadas de categorias, e são organizadas de acordo com os temas claramente definidos e conforme a relação que os mantém, sempre respeitando os objetivos propostos na pesquisa. Essas categorias facilitam a compreensão e interpretação dos dados. A partir disso, neste estudo, criou-se categorias de dados, através da sua análise e interpretação, encontrados tanto em literatura como nos questionários. A triangulação deste estudo foi baseada na triangulação de fontes, na triangulação interna e na reflexiva, buscando compreender de forma total os dados que foram coletados no campo de pesquisa.

\section{RESULTADOS}

Na Figura 1. Podemos observar o período da faculdade que os alunos estavam cursando.

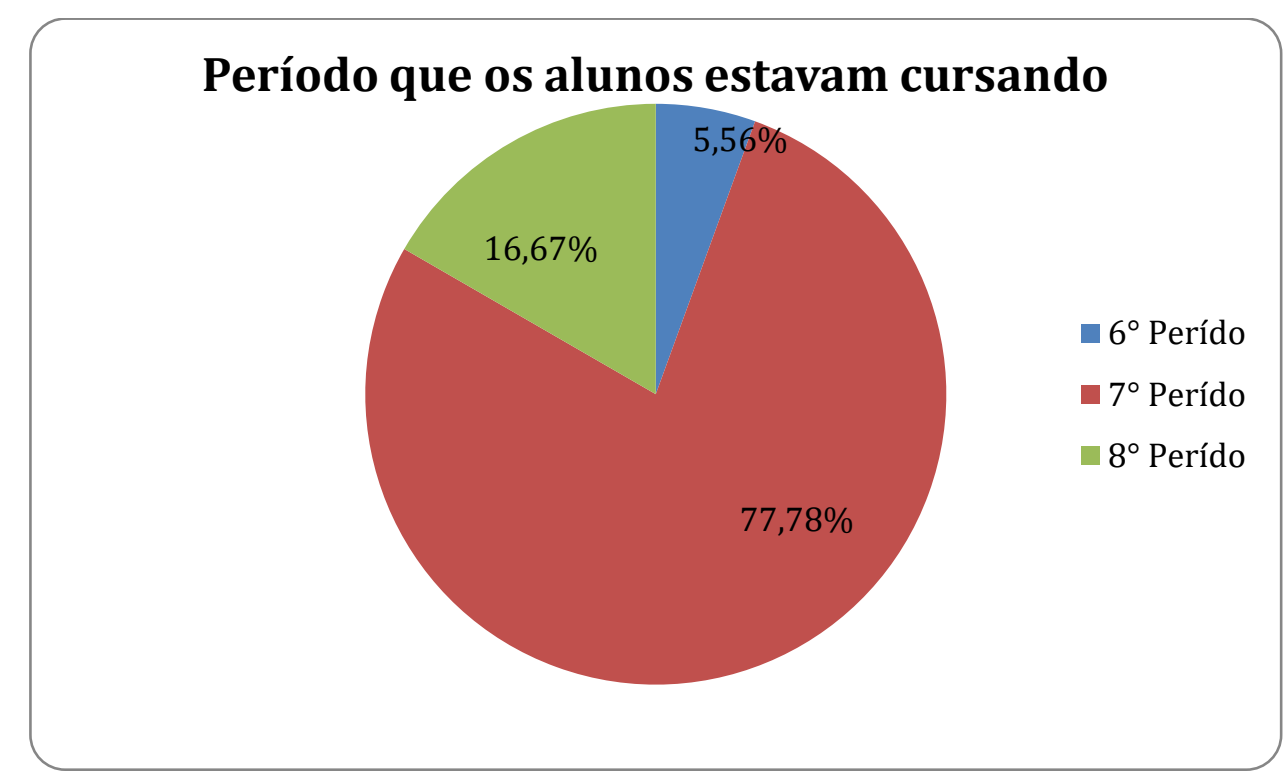

Figura 1 - Período que os alunos estavam cursando.

Fonte: Elaboração própria. 


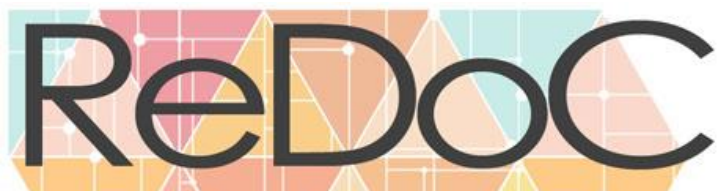

Revista Docência e Cibercultura

Dezessete participantes eram do sexo feminino e apenas um participante do sexo masculino, com idades entre 21 e 24 anos. Cursavam entre o sexto e o oitavo período, a grande maioria estava no sétimo período.

Na Figura 2 é possível verificar a quantidade de disciplinas na área da Educação Especial e Inclusiva realizadas pelos graduandos do curso de Pedagogia até o momento da aplicação do questionário.

\section{Quantidade de disciplinas realizadas}

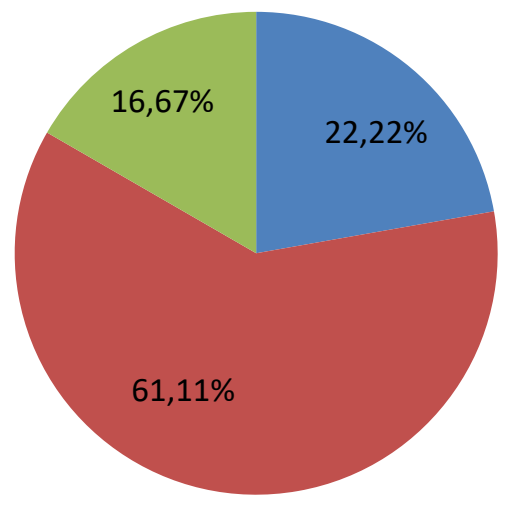

2 materias

- 3 materias

4 materias

Figura 2 - Quantidade de disciplinas na área da Educação Especial e Inclusiva realizadas entre o sexto e oitavo período.

Fonte: Elaboração própria.

A maioria dos estudantes já havia cursado 3 ou mais disciplinas na área da Educação Especial e Inclusiva.

O curso de pedagogia da universidade, possui em sua grade curricular três disciplinas obrigatórias que abrangem a temática da Educação Especial e Inclusiva. São elas: Educação inclusiva e a Língua Brasileira de Sinais; Questões Atuais em Educação Especial (QAEE); e Educação Inclusiva e Cotidiano Escolar (EICE), formando um total de 150 horas. Com relação ao conceito de TA, as disciplinas QAEE e EICE abordam na ementa o tema das adaptações curriculares e modelos de atendimento, os quais abrem a possibilidade para a introdução de 


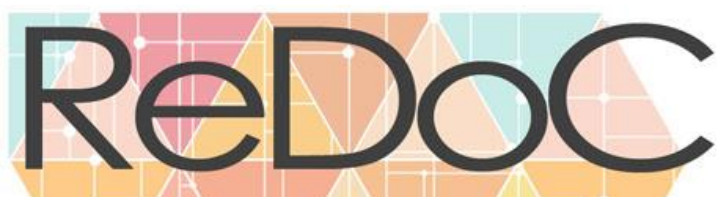

\section{Revista Docência e Cibercultura}

conceitos de acessibilidade, acessibilidade curricular, atendimento educacional especializado que envolvem a discussão dos recursos e serviços da TA.

Com as variações de oferta de disciplinas eletivas em cada semestre, ainda foi possível encontrar pelo menos uma eletiva da área da Educação Especial e Inclusiva oferecida em cada turno. As disciplinas eletivas da área da Educação Especial e Inclusiva mais comumente ofertadas foram: Atendimento Escolar no Ambiente Hospitalar, Linguagem e Comunicação Alternativa, Portadores de Necessidades Educacionais Especiais e seu Desenvolvimento em Contexto Sociocultural e LIBRAS. Apenas a disciplina Linguagem e Comunicação Alternativa faz referência a TA, enfatizando e aprofundando a categoria da Comunicação Alternativa, mas dando a possibilidade para se discutir a adaptação de materiais pedagógicos e a informática acessível.

Existe outro componente curricular que o aluno pode experenciar. As disciplinas intituladas Pesquisa e Práticas Pedagógicas. Estas são componentes curriculares do curso de Pedagogia, desenvolvidas a partir do terceiro período, até o sexto período do curso, somando 240 horas. Cabe a essas disciplinas a integração dos diversos componentes curriculares, tanto quanto a consolidação dos campos de formação e a articulação entre a formação teórica e as experiências práticas do estágio curricular (SCHIRMER, 2012, 2012). As disciplinas de PPP são eletivas restritas, portanto o graduando escolhe qual a PPP que irá cursar, ou seja, a disciplina pode ou não ser da área da Educação Especial e Inclusiva. No caso dos participantes deste estudo nenhum cursou a disciplina PPP na área da Educação Especial e Inclusiva. Sendo que alguns alunos referiram que ela não foi ofertada para eles.

Na Figura 3. pode-se verificar a percepção dos alunos quanto a estarem preparados para atuarem em uma sala de aula na perspectiva inclusiva. 


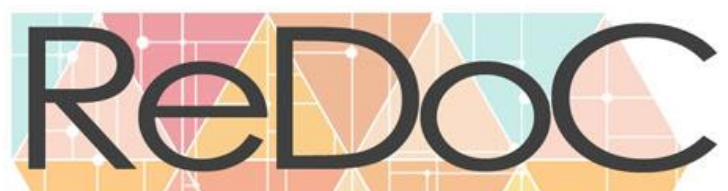

Revista Docência e Cibercultura

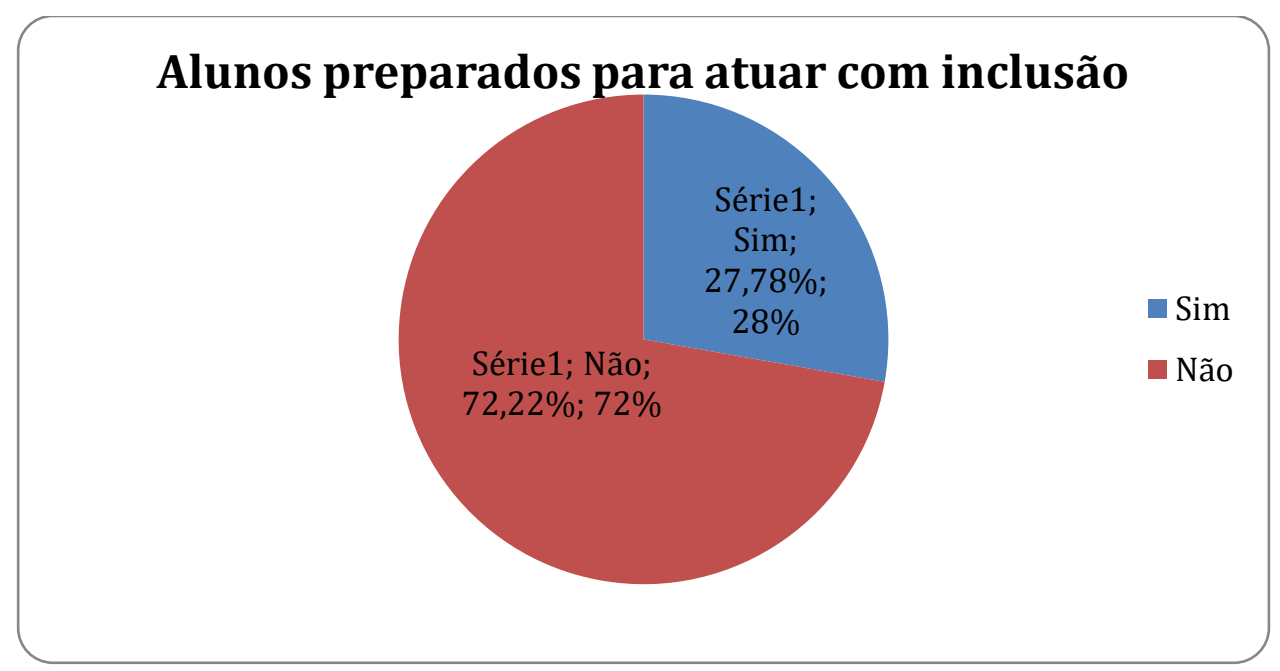

Figura 3 - Alunos que se sentem preparados ou não para atuar em uma sala de aula inclusiva. Fonte: Elaboração própria.

$\mathrm{Na}$ Figura 3. O estudo revelou que, aproximadamente, $72 \%$ (14 alunos) dos alunos demonstraram não se sentirem preparados para atuar em uma sala de aula inclusiva. Vários graduandos, em seus questionários, explicitaram os motivos pelo quais não se sentem aptos a atuar em um ambiente de inclusão. Vários pontuaram a pouca carga horária que essas disciplinas têm, proporcionando um aprendizado "mais superficial" sobre os temas que giram em torno da Educação Especial e Inclusiva como podemos observar na fala do aluno M.:

“As abordagens são gerais nas disciplinas obrigatórias. Nas disciplinas que cursei, pouco se falou das necessidades especiais de maneira específica e aprofundada." (M. $7^{\circ}$ período).

Uma opção que os graduandos teriam, devido ao número pequeno de disciplinas obrigatórias, seria buscar ampliar o conhecimento através das disciplinas eletivas, que poderiam complementar as informações das disciplinas obrigatórias.

Na Figura 4, observamos se os graduandos consideraram o número de eletivas ofertadas suficientes para a sua formação. 


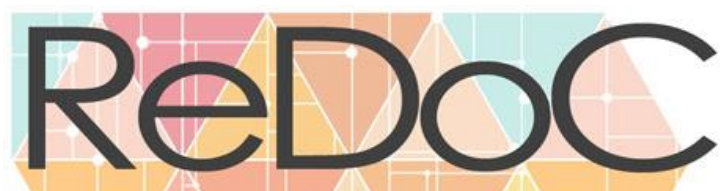

Revista Docência e Cibercultura

\section{Número de eletivas foram suficientes}

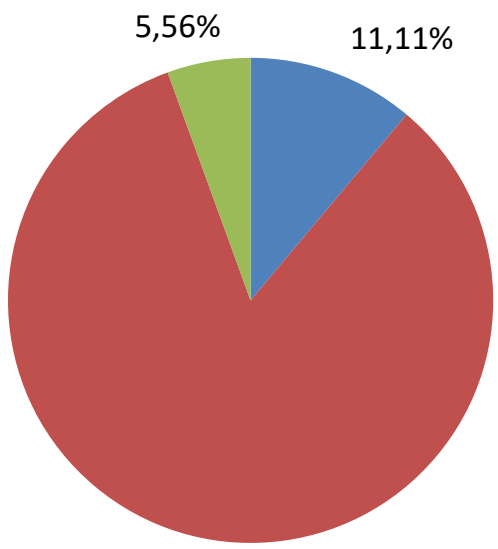

Acham suficientes

- Não acham suficientes

Não soube responder

$83,33 \%$

Figura 4 - Quantidade de disciplinas eletivas que foram suficientes Fonte: Elaboração própria.

O que percebemos é que os graduandos em sua maioria acham o número de disciplinas insuficientes. Os questionários ainda revelam outras questões: "nas disciplinas eletivas temos o mesmo conteúdo das obrigatórias", "a mesma ementa”, "os mesmos temas abordados em duas matérias distintas". Dentre essas pessoas que alegaram insatisfação, temos a fala do aluno R. ( $7^{\circ}$ período):

"O problema é que as vezes, as eletivas são aulas semelhantes às obrigatórias". (R. $7^{\circ}$ período).

O que indica que os conteúdos dessas disciplinas oferecidas são abrangentes, gerais e repetitivos segundo a percepção dos alunos de graduação.

$\mathrm{Na}$ Figura 5. pode se verificar a quantidade de alunos que fizeram apenas disciplinas obrigatórias e quantidade de alunos participantes que além das obrigatórias buscaram disciplinas eletivas. 


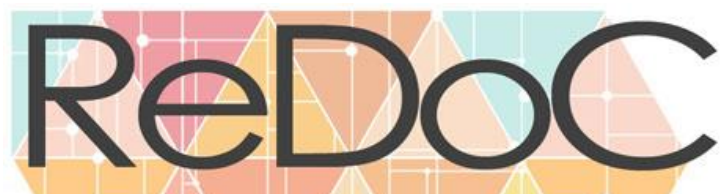

Revista Docência e Cibercultura

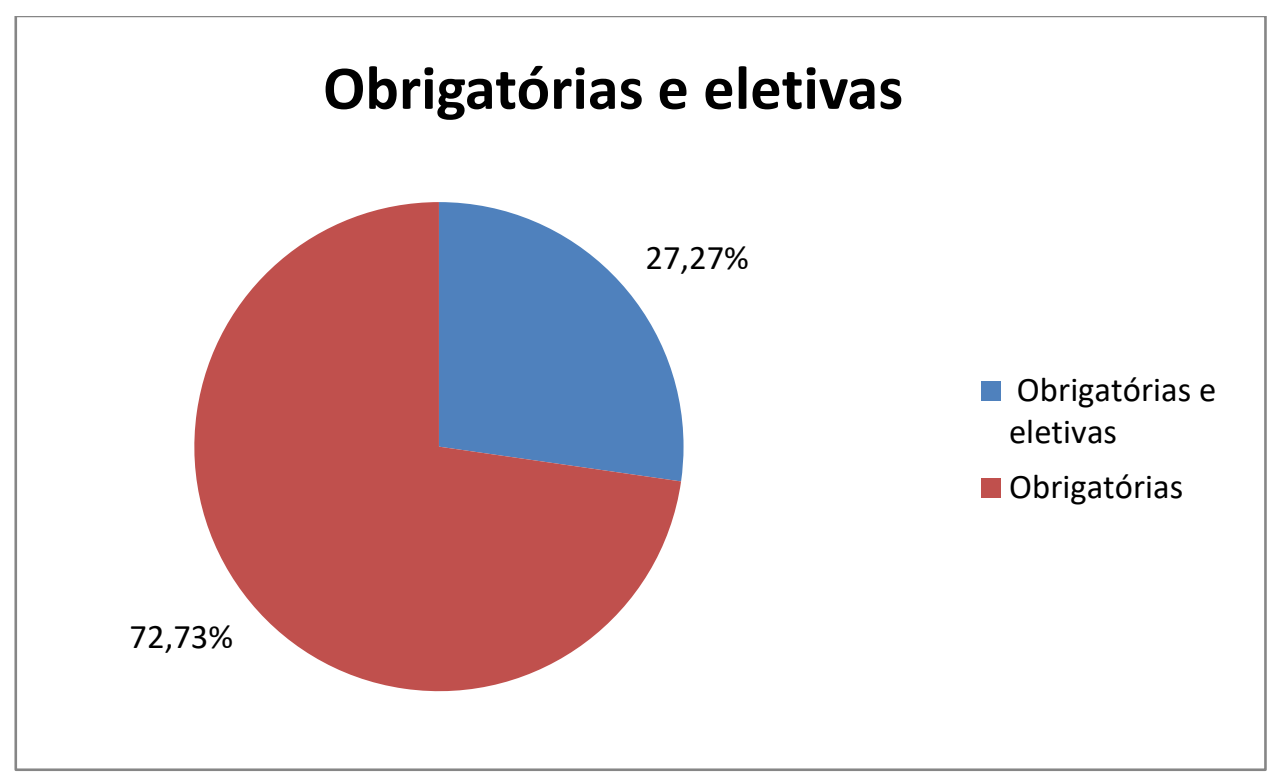

Figura 5 - Quantidade de graduandos que fizeram apenas disciplinas obrigatórias versus quantidade de graduandos que além das obrigatórias buscaram disciplinas eletivas.

Fonte: Elaboração própria.

Os dados da Figura 5, parecem sugerir que há um desinteresse e/ou a desmotivação pelas disciplinas eletivas da área da Educação Especial e Inclusiva, que poderiam complementar a formação inicial. As justificativas dos graduandos seriam estas restrições nas ofertas de disciplinas, pois não há uma regularidade de aberturas por semestre que possibilitem a participação de todos e ainda a repetição de conteúdos abordados e a repetição de disciplinas eletivas.

Outro aspecto que vale ressaltar é o fato de que o curso de Pedagogia da Faculdade de Educação, segundo os graduandos "é muito teórico" e não proporciona nenhuma experiência prática que ofereça conhecimento desses alunos com deficiência ou NEEs em sala de aula, a não ser para os alunos que escolham fazer a PPP nesta área. Quase a totalidade dos alunos salientaram a importância de inserção de estágio na área da Educação Especial e Inclusiva no currículo. Dentre a maioria que ressaltou a importância dessa inserção cito a fala da aluna T. ( $7^{\circ}$ período):

“A experiência com a Educação Inclusiva é muito importante para a formação de um pedagogo humanizado e sensível as especificidades dos alunos" (T. $7^{\circ}$ período). 


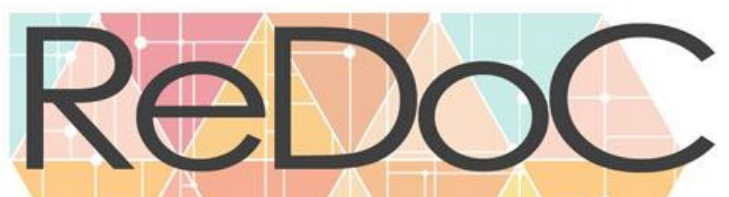

\section{Revista Docência e Cibercultura}

Para ilustrar das falhas no currículo e disciplinas trazemos a fala da aluna:

"Recebei um aluno deficiente auditivo e não tinha conhecimento algum sobre D.A. e nem o apoio escolar. O mesmo ficou apenas uma semana na escola". (L. $7^{\circ}$ período).

Cabe ressaltar que existe a disciplina de LIBRAS no currículo, porém ela tem apenas 30h e hoje é ofertada no primeiro período. Sendo que a maioria dos alunos inicia a fazer estágio entre o sexto e sétimo período.

A Figura 6. apresenta a percepção dos docentes se as disciplinas cursadas forneceram base teórico prática considerada suficiente para que eles atuem em uma sala de aula inclusiva.

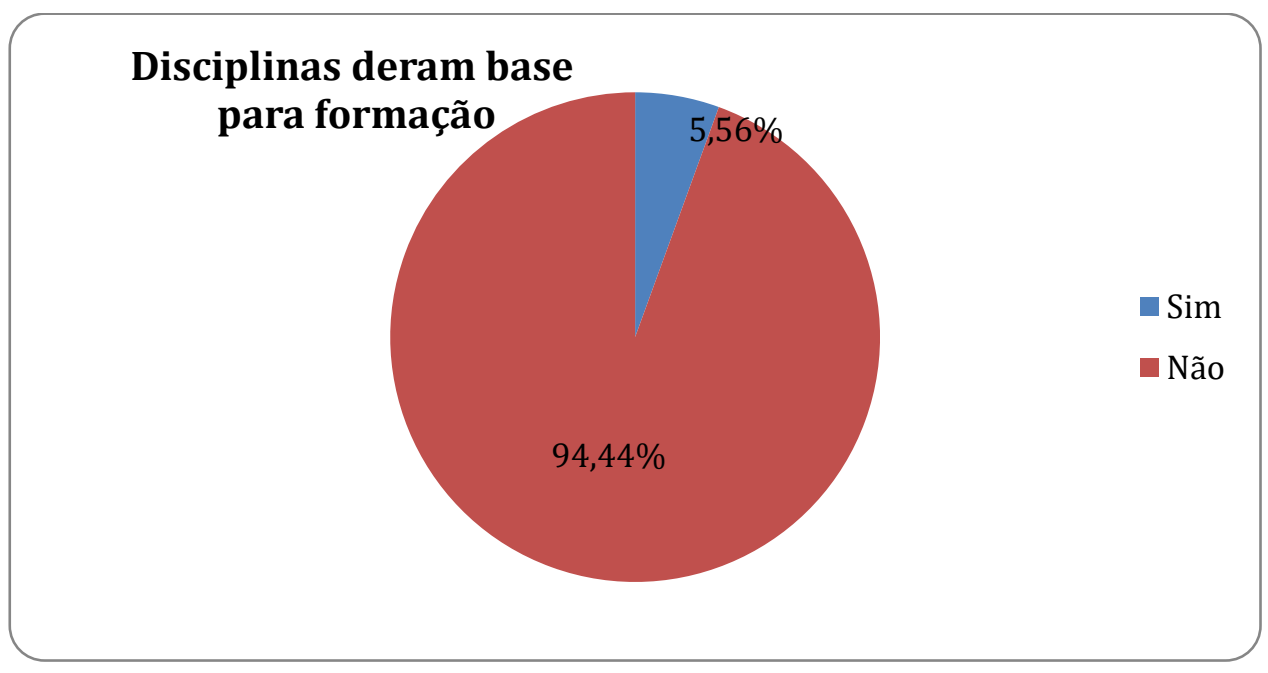

Figura 6 - mostra se as disciplinas cursadas forneceram base ou não para que os graduandos possam atuar dentro de uma sala de aula inclusiva.

Fonte: Elaboração própria.

Os dados da Figura 6 sugerem que a maioria dos alunos pensa que as disciplinas cursadas na área da Educação Especial e Inclusiva não proporcionaram conhecimento teórico e prático para que eles atuem dentro de uma perspectiva inclusiva. Uma das participantes pontua:

"Acredito que os graduandos que forem trabalhar com alunos com necessidades especiais, precisam buscar mecanismos/formação, além das que temos na grade curricular" (M.G. $7^{\circ}$ período).

\section{DISCUSSÃO}


Em síntese, a maioria dos participantes eram do sexo feminino, que estavam no sétimo período do Curso de Pedagogia, com idades entre 21 e 24 anos. Os resultados sugerem que os graduandos de fato não se sentem preparados para atuar com alunos com deficiência e outras NEEs. Trazem ainda pontos importantes para a reflexão sobre o currículo oferecido. Seriam eles: a reorganização das ementas das disciplinas a fim de evitar que um mesmo conteúdo seja dado em mais de uma disciplina, oferta mais diversificada de eletivas, inserção de disciplina de práticas pedagógicas e de estágio curricular na área.

Vale ressaltar, que cabe aos cursos de formação inicial de professores uma proposta pedagógica direcionada à diversidade, afinal, “[...] a universidade é um lugar onde os valores e práticas de educação inclusiva precisam ser vivenciadas" (CASTANHO; FREITAS, 2005, p. 85). Por mais que na teoria a Faculdade de Educação pareça estar ofertando um currículo que busca a capacitação de seus graduandos para a diversidade, podemos pontuar que na prática as coisas se tornam diferentes. Vários estudos discutem essa separação disciplinar que ocorre na organização curricular nos cursos de formação de professores bem como a falta de articulação entre a teoria e a prática (FREITAS; MOREIRA, 2009; ANTUNES; GLAT, 2011).

O que se sabe é que esse fracionamento reproduzido pelo currículo não permite que ao docente em formação desenvolver uma prática pedagógica contextualizada com a realizada educacional brasileira (ANTUNES; GLAT, 2011). Para Calheiros et al. (2018) as práticas pedagógicas vivenciadas pelo professor durante o processo de formação podem influenciar no aprendizado dos seus estudantes e na construção de um ambiente escolar inclusivo.

Sabemos que tradicionalmente, os cursos de formação inicial de professores não abrangem conhecimentos tão específicos e diversificados que possam sustentar com efetividade o trabalho docente para o uso de recursos de TA (CASTRO; SOUZA; SANTOS, 2011; MANZINI, 2013; CALHEIROS; MENDES; FERREIRA, 2018). Analisando as disciplinas do curso de Pedagogia encontramos apenas a disciplina eletiva Linguagem e Comunicação Alternativa que aborda a TA de forma especifica, nas demais ementas verificamos que apenas são citadas as adaptações curriculares (AC) e estruturais. As AC são os importantes “ajustes" 


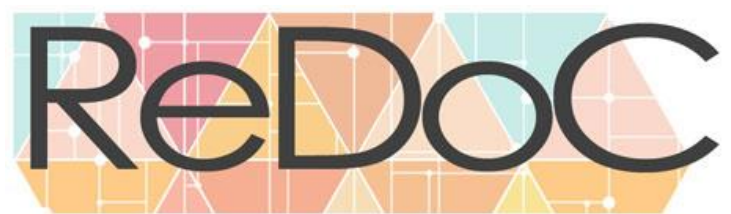

\section{Revista Docência e Cibercultura}

realizados no currículo, para que ele se torne apropriado ao acolhimento das diversidades dos alunos (OLIVEIRA; MACHADO, 2007). Envolvem modificações organizativas: nos objetivos e conteúdos, nas metodologias, na organização didática, na organização do tempo, na filosofia e estratégias de avaliação. São as transformações que a escola precisa fazer para garantir a acessibilidade aos alunos quanto às adaptações pedagógicas ou curriculares propriamente ditas (CORREIA, 2003).

As adaptações de acessibilidade curricular são diferentes das adaptações pedagógicas ou curriculares propriamente ditas. E falar de acessibilidade implica em tratar de TA. A Comunicação Alternativa (CA) é uma área de conhecimento, considerada uma modalidade de TA, que abrange as questões do campo da Linguagem e da Tecnologia Assistiva. Engloba sistemas de comunicação suplementar e alternativa que tem o objetivo de complementar, potencializar e ou substituir a fala ou a escrita de pessoas com deficiência e necessidades complexas de comunicação ou seja sem fala e/ou escrita funcional. Estes sistemas ampliam as possibilidades de desenvolvimento da recepção, compreensão e expressão da linguagem desses sujeitos (MASSARO; DELIBERATO, 2017). Portanto se pensamos nas adaptações de acessibilidade para a comunicação estamos falando na necessidade da implementação dos recursos, estratégias e metodologias da CA. Também existem outras categorias de TA, que tem o objetivo promover a funcionalidade e participação das pessoas com deficiência ou envelhecimento em outras atividades (CALHEIROS et al., 2018). São elas: Auxílios para a vida diária e vida prática; informática acessível; adequação postural (posicionamento para função); auxílios de mobilidade; sistemas de controle de ambiente; projetos arquitetônicos para acessibilidade; recursos para cegos ou para pessoas com visão subnormal; recursos para surdos ou pessoas com déficits auditivos e adaptações em veículos (PELOSI, 2008).

Para Borges e Tartucci (2017) a aplicação dos conhecimentos de TA ganha grande relevância quando pensamos nos processos de ensino e aprendizagem a que as crianças são submetidas na fase escolar e por isso necessários na graduação de Pedagogia.

Gatti (2013) e Cortelazzo (2012) descrevem que muitos cursos de licenciatura oferecem apenas uma disciplina sobre educação especial ou sobre fundamentos da educação especial 
com carga horária de 30 horas em caráter eletivo. No que tange à Faculdade de Educação da universidade estudada como um todo, o currículo apresenta um número de disciplinas obrigatórias com significante carga horária em relação a outros cursos. Porém, como forma de ser melhor aproveitada a carga horária já disponibilizada, segundo os graduandos que participaram do estudo, o ideal seria que houvesse uma maior interação dentro do departamento e uma elaboração conjunta das ementas das disciplinas, buscando evitar a repetição de conteúdos para que uma gama maior de informações diferentes fosse ensinada. Incluir nas ementas a TA também seria importante para garantir as discussões sobre o tema com os futuros docentes.

Nas sugestões dos graduandos surge outra hipótese de solução, seria uma oferta diversificada de eletivas na área ou uma disciplina eletiva apenas para estudos de caso, que ajudariam na prática dos mesmos. Isso evitaria a insegurança dos alunos em como lidar com as especificidades de cada aula incluído.

Poker afirma ainda que:

“[...] em muitos casos, os professores recém-formados saem da faculdade com ideias equivocadas e simplistas a respeito do paradigma da inclusão social e educacional, reduzindo o conceito de inclusão ao fato de aceitar alunos deficientes em suas classes". (POKER, 2003, p. 44)

Por fim, seria fundamental para que toda essa teoria fosse internalizada, que os alunos pudessem aplicá-las a uma prática. Buscando então, que fosse inserido no currículo um estágio obrigatório específico para educação especial. Poker et al. (2017) desenvolveu um estudo com o objetivo de identificar, junto aos estudantes egressos do curso de Pedagogia, quais eram suas percepções sobre tal curso de formação inicial e verificar se o mesmo promoveu uma formação em direção à educação inclusiva. Os resultados sugeriram, assim como em nosso estudo, a necessidade de reestruturação curricular do curso de forma a priorizar a relação entre as disciplinas que tratam de conteúdos de Educação Especial e as demais, além da inserção de oportunidades de estágio em salas de aulas inclusivas para aprimorar a formação do professor. 
Tudo isso buscaria evitar a falta de preparo dos graduandos, onde a formação inicial se tornaria mais adequada para os desafios encontrados nas salas de aula, minimizando relatos que demonstram a falta de experiências, onde professores não souberam lidar com esses alunos.

Segundo Manzini (2012) com o processo de inclusão educacional será necessário que o docente, que atua com alunos com deficiência, conheça e domine os recursos de Tecnologia Assistiva disponíveis no mercado brasileiro. Cortelazzo (2012) também discute as mudanças necessárias para que a escola se torne inclusiva e nelas cita o déficit na formação docente e na necessidade de que os professores incorporarem a utilização da TA na prática educacional.

\section{CONSIDERAÇÕES FINAIS}

Os dados apresentados sugerem que os graduandos de fato não se sentem preparados para atuar com alunos com deficiência e outras NEEs. Trazem ainda pontos importantes para a reflexão sobre o currículo oferecido. Seriam eles: a reorganização das ementas das disciplinas a fim de evitar que um mesmo conteúdo seja dado em mais de uma disciplina, oferta mais diversificada de eletivas na área da Educação Especial e Inclusiva, inserção de disciplina de práticas pedagógicas e de estágio curricular na área da Educação Especial e Inclusiva além da necessidade de ampliar as discussões sobre TA no currículo dos futuros pedagogos.

Concluimos, ressaltando, que a Educação Especial tem galgado sempre buscar inovações que busquem atender os seus direitos e suas participações ativas nos processos educativos. A partir disso, podemos perceber que uma formação inicial que abranja essa temática é imprescindível para dar base, mas que é sempre necessário buscar mais e se atualizar para atuar com alunos com necessidades educacionais especiais.

Acreditamos que mais estudos na área da formação inicial de professores em Educação Especial e Inclusiva que discutam a TA devam ser realizados. Pois as pesquisas revelam a urgência de que o professor se aproprie da TA e modifique suas concepções sobre a deficiência e, principalmente, modifique sua prática educacional para que possamos ter uma escola inclusiva de fato. 


\section{REFERÊNCIAS}

ANTUNES, K.C.V.;GLAT, R. Formação de professores na perspectiva da educação inclusiva: os cursos de pedagogia em foco. In: PLETSCH, M.D.; DAMASCENO, A. Educação Especial: reflexões sobre o fazer pedagógico. Serópédica: EDUR, 2011, p.149-160.

BARDIN, L. Análise de conteúdo. Tradução de Luís Reto e Augusto Pinheiro. Lisboa: Edições 70, 1997.

BERSCH, Rita. Design de um serviço de tecnologia assistiva em escolas públicas. Orientador: Vilson João Batista. 231 f.. Dissertação , Programa de Pós-Graduação em Design. (Mestrado em Design), Universidade Federal do Rio Grande do Porto Alegre, 2009.

BORGES, Wanessa Ferreira; TARTUCI, Dulcéria. Tecnologia Assistiva: Concepções de Professores e as Problematizações Geradas pela Imprecisão Conceitual. Revista Brasileira de Educação Especial. Marília, vol.23, n.1, p.81-96, Janeiro-Março/2017.

BRASIL. Ministério da Educação. Diretrizes Nacionais para a Educação Especial na Educação Básica. Parecer CEB/CNE 17/2001, homologação publicada no DOU 17/08/2001, Seção 1, p. 46. Resolução CNE/CEB 02/2001, publicada no DOU 14/09/2001, Seção 1, p. 39.

BRASIL. Ata da Reunião VII, de dezembro de 2007. Comitê de Ajudas Técnicas. Secretaria Especial dos Direitos Humanos da Presidência da República (CORDE/SEDH/PR) Disponível em:<http://www.mj.gov.br/corde/arquivos/doc/Ata_VII_Reunião_do_Comite_de_Ajudas_Té cnicas.doc $>$ Acesso em: 27 de outubro de 2019.

BUENO, J. G. S. A educação inclusiva e as novas exigências para a formação de professores: algumas considerações. In: BICUDO, M.A.; SILVA Jr., C.A. (Orgs.) Formação de educadores e avaliação educacional. São Paulo: UNESP, 1999, p. 146-164.

CALHEIROS, D. dos Santos; MENDES, Enicéia Gonçalves; LOURENÇO, Gerusa Ferreira; GONÇALVES, Adriana Garcia; MANZINI, Mariana Gurian. Consultoria colaborativa a distância em tecnologia assistiva para professoras: planejamento, implementação e avaliação de um caso. Pro-Posições, Campinas, SP, V. 30, p.1-30, Abril/2019. Disponível em: <http://dx. doi.org/10.1590/1980-6248-2016-0085. Acesso em: 27 de outubro de 2019.

CASTRO, A. S. A.; SOUZA, L. R.; SANTOS, M. C. Proposições Teóricas para a Inclusão da Tecnologia Assistiva no Currículo Escolar da Educação Básica. Sitientibus, Feira de Santana, n. 44, p. $145-158,2011$.

CASTANHO, D. M.; FREITAS, S. N. Inclusão e prática docente no ensino superior. Revista Educação Especial, n. 27, p. 85-92, 2005. Disponível em: <http://coralx.ufsm.br/revce/ceesp/2006/01/a6.htm>. Acesso em: 23 jul. 2018 
CORTELAZZO, I. B. C. Formação de professores para uma educação inclusiva mediada pelas tecnologias. In: GIROTO, C. R. M.; POKER, R.B., OMOTE, S. (Org.). As tecnologias nas práticas pedagógicas inclusivas, São Paulo: Cultura Acadêmica, 2012, p.93 -120.

GATTI, B. A. A formação inicial de professores para a educação básica: as licenciaturas. Revista USP, n. 100, p. 33-46, dez./jan./fev. 2013-2014. Disponível em: <http://www.revistas.usp.br/revusp/article/view/76164>. Acesso em: 23 jul. 2018

MANZINI, Eduardo José. Formação do professor para trabalhar com recursos de tecnologia assistiva: um estudo de caso em Mato Grosso. Educação e Fronteiras. São Paulo, v. 2, n.5, p. 98-113, maio-agosto/2012.

MANZINI, Eduardo José. Formação do professor para o uso de tecnologia assistiva. Cadernos de Pesquisa em Educação, Vitória, v. 18, n. 36, p. 11-36, jul./dez. 2013.

MOLINA NETO, V. Etnografia: uma opção metodológica para alguns problemas de investigação no âmbito da Educação Física. In: SANCHO, Juana M. et al. A pesquisa qualitativa na educação física: alternativas metodológicas. Porto Alegre: Editora da Universidade, Sulina, 1999. p.141.

PEDROSO, C. C. A.; CAMPOS, J. A. P. P.; DUARTE, M. Formação de professores e educação inclusiva: análise das matrizes curriculares dos cursos de licenciatura. Educação Unisinos, v. 17, n. 1, p. 40-47, jan./abr. 2013.

PELOSI, M.B. Inclusão e Tecnologia Assistiva. Tese (Doutorado em Educação) defendida

no Programa de Pós-Graduação em Educação, Universidade do Estado do Rio de Janeiro. Rio

de Janeiro, 2008.

PLETSCH, M. D. A formação de professores para a educação inclusiva: legislação, diretrizes políticas e resultados de pesquisas. Revista Educar, n. 33, p. 143-156, 2009.

POKER, R. B. Pedagogia inclusiva: nova perspectiva na formação de professores. Educação em Revista: formação de profissionais na educação, n. 4, p. 39-50, 2003.

POKER, R. B.; VALENTIM, F. O. D.; GARLA, I. A. Inclusão escolar e formação inicial de professores: a percepção de alunos egressos de um curso de Pedagogia. Revista Eletrônica de Educação, v.11, n.3, p.876-889, set./dez., 2017

SCHIRMER, C. R. R. Metodologia Problematizadora na formação de graduandos de Pedagogia em Comunicação Alternativa. 2012. 207f. Tese (Doutorado em Educação) Programa de Pós-Graduação em Educação, Faculdade de Educação, Universidade do Estado do Rio de Janeiro, Rio de Janeiro, 2012. 